УДК 616.89-008.441.33-055.1/2

Для цитирования: Шигакова Ф.А. Роль гендерных различий в механизмах формирования опийной наркомании. Сибирский вестник психиатрии и наркологии. 2017; 3 (96): 21-26. https://doi.org/10.26617/1810-3111-2017-3(96)-21-26

\title{
Роль гендерных различий в механизмах формирования опийной наркомании Шигакова Ф.А.
}

Ташкентский институт усовершенствования врачей

Узбекистан, 100007, Ташкент, ул. Паркент, 51

\section{PEЗЮME}

Цель: Анализ причин и механизмов развития опийной наркомании с учетом гендерных различий. Материал: в Республиканском наркологическом центре в 2010-2015 гг. пролечено 131 больной опийной наркоманией. Основная группа - 66 женщин 18-56 лет. Группа сравнения - 65 мужчин 23-50 лет. Результаты: корреляционный анализ причин и механизмов формирования опийной наркомании с учетом гендерных различий выявил достоверную корреляцию $(\mathrm{r}=0,31 ; \mathrm{p}=0,003)$ между полом и наследственной отягощенностью, возрастом употребления алкоголя и полом $(\mathrm{r}=0,23 ; \mathrm{p}=0,02)$. Достоверно большее количество женщин впервые приняли наркотик в компании наркозависимых друзей своего наркозависимого мужа или сожителя. Значимыми факторами явилось то, что достоверно большее количество женщин начали первый приём опиатов с героина, который отличается самой высокой наркогенностью среди опиатов. У многих больных ещё до формирования опийной наркомании имели место признаки девиантного поведения. Отсутствие девиантного поведения достоверно чаще наблюдалось у мужчин (75,4\% мужчин и 57,6\% женщин; ОШ 2,26; $95 \%$ ДИ 1,07-4,76; p=0,05) по сравнению с женщинами. Ещё до формирования наркомании более половины исследуемых женщин не занимались трудовой деятельностью, тогда как почти все мужчины были заняты в различных сферах деятельности.

Ключевые слова: пол, корреляция, гендерные различия, опийная наркомания.

\section{ВВЕДЕНИЕ}

Изучение механизмов формирования зависимости от психоактивных веществ является актуальным направлением психиатрии и наркологии в связи с высокой распространенностью и социальной значимостью данного заболевания. Важное влияние на формирование заболевания оказывает целый комплекс предшествующих биологических и социальных факторов. Ряд авторов указывает на большое количество факторов риска для возникновения мотивации на потребление наркотиков $[3,4,6]$. К этим факторам относятся: наследственная отягощенность наркотическими и психическими заболеваниями, отсутствие эмоциональной связи, традиций и правильного уклада жизни в родительской семье, хаотический образ жизни, психопатическая структура личности со склонностью к импульсивным действиям, узость интересов, слабая мотивация к учебе [6].

Гендерные особенности наркоманической зависимости освещены в ряде исследований $[1,2]$. Однако в этих работах проблема различных аспектов полоролевого диморфизма больных наркоманией и гносеологическое поле их рассмотрения ограничивается сравнительным изучением наркологических характеристик в рамках дилеммы «женские - мужские». В большей степени изучены вопросы алкоголизма у женщин. Показано, что формирование и течение алкоголизма у женщин отличаются некоторыми особенностями [10].

По сравнению с мужчинами у женщин, страдающих наркоманиями, имеются определенные особенности в мотивации первого употребления наркотиков и приобщения к ним, видах предпочитаемых наркотиков, скорости формирования основных симптомов и синдромов наркомании, тяжести медицинских и социальных последствий $[5,9,11]$.
Большинство исследователей считают, что основным мотивом приобщения женщин к наркотикам является влияние мужчин, употребляющих наркотики, преимущественно сексуальных партнеров $[8,12$, $13,14,15,16]$.

Цель исследования. Анализ причин и механизмов развития опийной наркомании с учетом гендерных различий.

\section{МАТЕРИАЛЫ И МЕТОДЫ}

Изученную выборку составили 131 больной опийной наркоманией, проходивших стационарное лечение в Республиканском наркологическом центре с 2010 по 2015 г. Основную группу составили 66 женщин в возрасте от 18 до 56 лет. В группу сравнения вошли 65 мужчин от 23 до 50 лет. К моменту обследования средний возраст мужчин составил $35,6 \pm 5,6$ года, женщин - 34,0 10,5 года $(\mathrm{p}=0,28)$.

Критерии включения: пациенты с диагнозом по МКБ-10 «Психические расстройства и расстройства поведения, вызванные употреблением опиоидов; синдром зависимости (код F11.2); синдром отмены, обусловленный употреблением опиоидов (код F11.30); возраст больных от 18 до 56 лет.

Критерии исключения: случаи сочетанного употребления разных наркотиков.

Стаж потребления героина преимущественно находился в диапазоне от 5 до 15 лет как у женщин $(42-63,6 \%)$, так и у мужчин $(42-64,6 \%)$.

У всех больных была диагностирована II стадия героиновой наркомании в соответствии с классификацией И.Н. Пятницкой [1994, 2002]. Непосредственное клиническое изучение больных сочеталось с ретроспективным анализом анамнестических данных и объективных сведений, изучением историй болезни предшествующих госпитализаций, выписок из историй болезни лечебных учреждений общего 
профиля. Это давало возможность составить достаточно четкое представление об особенностях клиники и течения заболевания, видах и методах проведенной ранее терапии, клинических проявлениях наркомании в периоды воздержания от употребления наркотиков, а также условиях возникновения срывов и рецидивов опиомании. Также изучались анамнестические данные и объективные сведения, полученные от родственников больного и окружающих.

Полученные данные обрабатывали с помощью компьютерных программ Microsoft Excel, STATISTICA 6 и Biostat. Отношение шансов (ОШ) и 95\% доверительный интервал (95\% ДИ) рассчитывали с применением логистической регрессии. Достоверность различий показателей оценивали с помощью непараметрического критерия $\chi^{2}$ (критерий Пирсона). Количественные показатели представлены в виде $\mathrm{M} \pm \mathrm{SD}$, медианы (Me) и 25 и 75 перцентилей (IQR). Различия между группами считали статистически значимыми при $\mathrm{p}<0,05$. Корреляционный анализ проводился по Спирману.

\section{РЕЗУЛЬТАТЫ И ОБСУЖДЕНИЕ}

Анализ наследственной отягощенности, который проводился на основании оценки наличия или отсутствия психической патологии, алкоголизма и наркоманий у родственников I степени родства (родители, сибсы), показал, что наследственная отягощенность наркологической патологией (алкоголизм, наркомания) достоверно чаще встречалась в группе больных женщин $(39,4 \%$ женщин против $12,3 \%$ мужчин; ОШ 4,63; 95\% ДИ 1,90-11,3; $\mathrm{p}=0,001)$. Вместе с тем в исследуемых группах не зарегистрировано наследственной отягощенности по таким психическим заболеваниям, как шизофрения, психопатия (только у одной женщины мать страдала эпилепсией).

Выявлена достоверная корреляция (r=0,31; $\mathrm{p}=0,003)$ между полом и наследственной отягощенностью.

Анализ предшествующих соматических заболеваний выявил, что корреляции между наличием соматической патологии и полом не обнаружено $(\mathrm{r}=0,05 ; \mathrm{p}=0,57)$.

Кроме предшествовавшей соматической патологии необходимо учитывать и экзогенные вредности, которые могли иметь место ещё до приобщения пациентов к препаратам опиоидного ряда. Анализ наркологического анамнеза исследуемых больных показал, что основная часть не только мужчин, но и женщин в качестве первых в своей жизни эйфоризирующих средств употребляли алкоголь, почти половина исследуемых мужчин - гашиш. Из числа обследуемых 8 (12,3\%) мужчин и $10(15,2 \%)$ женщин при опросе отрицали употребление алкоголя, $3(4,6 \%)$ мужчин и $6(9,1 \%)$ женщин не смогли указать точный возраст первого приема спиртных напитков, ссылаясь на забывчивость. В обеих группах дальнейшее употребление алкоголя носило эпизодический характер.
Основная часть мужчин $(83,1 \%)$ и женщин (75,8\%), пробовавших алкоголь, указывают на первый приём алкогольных напитков в возрасте от 15 до 20 лет $(64,6 \%$ мужчин и 51,5\% женщин; $\mathrm{p}=0,18)$. Первые пробы алкоголя в возрасте до 15 лет наблюдались как в группе мужчин, так и в группе женщин $(13,8 \%$ мужчин и $9,1 \%$ женщин; $\mathrm{p}=0,56)$. Среди употребивших впервые алкогольные напитки после 20 лет заметно больше женщин, чем мужчин $(4,6 \%$ мужчин и $15,2 \%$ женщин; $\mathrm{p}=0,08)$. Средний возраст первого употребления алкоголя у больных мужчин составил $16,1 \pm 1,7$ года и был достоверно ниже, чем у женщин - 17,3 $\pm 2,5$ года $(\mathrm{p}=0,005)$.

Установлена слабая достоверная корреляция между возрастом первого употребления алкоголя и полом ( $\mathrm{r}=0,23 ; \mathrm{p}=0,02)$.

Интересные данные выявлены нами при анализе возраста и характера первого употребления гашиша. Первым наркотиком, к которому прибегали исследуемые, в $45(34,4 \%)$ случаях (из них 32 мужчины и 13 женщин) являлся гашиш. В группе женщин $80 \%$ больных, никогда не употребляли гашиш, тогда как в группе мужчин 49,3\% больных знакомство с наркотиками начали с употребления гашиша.

Из исследуемых больных мужчин (49,2\%) и женщин $(19,7 \%)$ знакомство с каннабиноидами чаще всего происходило в возрастном интервале от 15 до 20 лет (41,5\% мужчин и 10,6\% женщин; ОШ $5,99 ; 95 \%$ ДИ 2,37-15,1; $=0,001)$.

Приобщение к гашишу в возрасте до 15 лет в исследовательской выборке не наблюдалось. Случаи приема гашиша после 20 лет примерно с одинаковой частотой отмечались как в группе мужчин, так и в группе женщин (7,7\% мужчин и $6,1 \%$ женщин; $\mathrm{p}=0,98)$. Средний возраст первого употребления га-

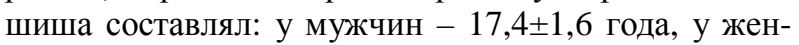
щин - $18,7 \pm 4,7$ года $(\mathrm{p}=0,17)$.

У большинства больных мужчин и женщин первый прием гашиша сопровождался развитием эйфории $(84,3 \%$ мужчин и $77 \%$ женщин; $\mathrm{p}=0,40)$, у остальной части обследуемых курение гашиша первоначально вызывало выраженную защитную реакцию организма в виде тошноты, рвоты, слабости, головной боли $(15,7 \%$ мужчин и $33 \%$ женщин; $\mathrm{p}=0,03)$ (табл. 1).

Т а б ли ц а 1 Распределение больных в зависимости от характера употребления гашиша до формирования опийной наркомании

\begin{tabular}{|c|c|c|c|c|c|c|c|}
\hline \multirow[t]{2}{*}{$\begin{array}{c}\text { Характер } \\
\text { употребления гашиша }\end{array}$} & \multicolumn{2}{|c|}{\begin{tabular}{|c|} 
Мужчины \\
$(\mathrm{n}=65)$
\end{tabular}} & \multicolumn{2}{|c|}{\begin{tabular}{|c|} 
Женщины \\
$(\mathrm{n}=66)$
\end{tabular}} & \multirow[t]{2}{*}{$\mathrm{p}$} & \multicolumn{2}{|c|}{$\begin{array}{c}\text { Всего } \\
(\mathrm{n}=131)\end{array}$} \\
\hline & aбc. & $\%$ & абс. & $\%$ & & абс. & $\%$ \\
\hline Никогда не употребляли & 33 & 50,8 & 53 & 80,3 & 0,001 & 86 & 65,6 \\
\hline Употребляли 1-2 раза & 5 & 7,7 & 3 & 4,5 & 0,69 & 8 & 6,2 \\
\hline $\begin{array}{l}\text { Эпизодическое } \\
\text { употребление }\end{array}$ & 27 & 41,5 & 10 & 15,2 & 0,002 & 37 & 28,2 \\
\hline Всего & 65 & 100,0 & 66 & 100,0 & & 131 & 100, \\
\hline
\end{tabular}

Данные таблицы 1 демонстрируют наличие в группе женщин $(80,3 \%)$ довольно большого количества лиц, которые никогда не принимали каннабиноиды (против 50,8\% в группе мужчин; ОШ $3,95 ; 95 \%$ ДИ 1,82-8,60; $\mathrm{p}=0,001)$. 
Напротив, в группе мужчин наблюдалось значительное количество лиц, прибегавших к курению гашиша (49,2\%). При этом 1-2 попытки курения гашиша мели место примерно у равного количества мужчин и женщин $(7,7 \%$ мужчин и $4,5 \%$ женщин; $\mathrm{p}=0,69)$. Употребляли гашиш эпизодически достоверно большее количество мужчин $(41,5 \%$ мужчин и 15,2\% женщин; ОШ 3,98; 95\% ДИ 1,73-9,16; $\mathrm{p}=0,002)$, чем женщин.

Между характером употребления гашиша до приобщения к опиатам и полом выявлена достоверная корреляция $(\mathrm{r}=0,29 ; \mathrm{p}=0,05)$.

Таким образом, частота приема каннабиноидов до формирования опийной наркомании в группе мужчин и женщин была различной, что, в свою очередь, могло повлиять на формирование опийной наркомании.

Исследование выявило, что больные мужчины и женщины впервые попробовали препараты опиоидного ряда в одном и том же возрастном диапазоне - от 20 до 30 лет (58,5\% мужчин и 43,9\% женщин; $\mathrm{p}=0,14)$. Если частота первого употребления опиатов в возрасте от 15 до 20 лет у мужчин и женщин не имела статистически достоверных различий (20\% мужчин и $30,3 \%$ женщин; $\mathrm{p}=0,25)$, то знакомство с опиатами в возрастном диапазоне от 20 до 40 лет достоверно реже встречалось в группе женщин $(60,6 \%)$, чем в группе мужчин $(78,5 \%$; ОШ 0,$42 ; 95 \%$ ДИ 0,20-0,91; p=0,04). Вместе с тем приобщение к опиатам после 40 лет было более характерно для женщин в сравнении с мужчинами $(1,5 \%$ мужчин и 9,7\% женщин; $\mathrm{p}=0,13)$.

Обнаружена слабая корреляция между возрастом первого приема опиата и полом ( $\mathrm{r}=0,06 ; \mathrm{p}=0,46)$.

Принимая во внимание тот факт, что большинство больных мужчин и женщин до первого приема опиатов ранее уже испытывали эйфоризирующй эффект других психоактивных веществ, можно предположить, что более важную роль в формировании опийной наркомании играл возраст первого знакомства с состоянием эйфории, независимо от того, каким веществом она было вызвана. Это предположение согласуется с возрастными показателями приобщения к алкоголю и характером потребления гашиша, которые имели более заметные гендерные различия, чем показатели возраста первого приёма опиатов.

Установлены гендерные различия по характеру ситуации, которая предрасполагала к первому приему опиатов. Подавляющее большинство мужчин $(89,2 \%)$, в отличие от женщин $(40,9 \%$; ОШ 12,$0 ; 95 \%$ ДИ 4,75-30,2; p=0,0001), опиаты употребили впервые в компании друзей, подруг, «по совету» которых принимали наркотик «из любопытства». Женщин, которые принимали наркотик впервые в компании наркозависимого сексуального партнера, оказалось больше $(13,6 \%)$, чем в группе мужчин $(1,5 \%$; ОШ 10,1; 95\% ДИ 1,24-82,2; p=0,02). Вне компании, под влиянием наркозависимого сожителя приняли опиаты 24 (36,4\%) женщины.
В этих случаях, как правило, наркозависимые сексуальные партнеры являлись инициаторами приобщения женщин к употреблению наркотика, тогда как в группе мужчин такого не наблюдалось. Из числа исследованных $6(9,1 \%)$ женщин впервые приняли наркотик под влиянием наркозависимых родственников (братьев, сестер). В группе мужчин $6(9,2 \%)$ больных впервые приняли опиаты на праздничном мероприятии, чаще это происходило на свадьбе в состоянии алкогольного опьянения. В группе женщин такого рода ситуаций вообще не зарегистрировано.

Препараты опия, приготовленные кустарным способом, в $27(20,6 \%)$ случаях (22 мужчины и 5 женщин) являлись первым наркотиком, с которым знакомились исследуемые. Как правило, это происходило под влиянием «опытного» друга-наркомана, который убеждал, что получить «кайф» можно только от того, что делается из мака. Наряду с побочными явлениями, связанными с передозировкой или низким качеством наркотика, основное значение подобный дебют имеет для прогредиентности наркомании, в силу различной наркогенности опийных веществ. В остальных случаях 104 (79,4\%) больных, причем из них достоверно чаще женщины (66\% мужчин и 92,4\% женщин; p=0,001), начали первый приём опиатов с героина, отличавшегося самой высокой наркогенностью среди всех опиатов.

В ходе исследования выявлены гендерные различия по способу первого приёма опиатов. Так, приём опиатов путем курения в группах мужчин и женщин был приблизительно одинаков $(33,9 \%$ мужчин и 24,3\% женщин; $\mathrm{p}=0,31)$, схожая ситуация наблюдалась и в отношении первого интраназального приема опиатов (36,9\% мужчин и 43,9\% женщин; $\mathrm{p}=0,31)$. Вместе с тем сравнительный анализ показал, что женщин, которые начали принимать героин сразу внутривенно, оказалось достоверно больше, чем мужчин $(9,2 \%$ мужчин и $27,3 \%$ женщин; ОШ 3,69; $95 \%$ ДИ 1,36-10,0; $=0,01)$. Что же касается перорального приёма опиатов, то этот путь приема достоверно чаще встречался среди мужчин по сравнению с женщинами (20\% мужчин и 4,5\% женщин; ОШ 5,25; $95 \%$ ДИ 1,42-19,4; $\mathrm{p}=0,01)$.

В механизмах формирования личностной патологии у больных наркоманиями, как и в развитии личности вообще, а также в формировании психолого-поведенческих свойств индивида немаловажную роль играют условия его воспитания и процессы социализации, система мотивов, побуждающих его к деятельности, которая складывается на основе совокупности потребностей, в том числе возникших в динамике болезни. Весьма существенным фактором, определяющим формирование «наркоманической» личности, является присутствие личностных девиаций в преморбиде, особенно «антисоциальная направленность личности», криминальность. В связи с чем в ходе исследования у всех больных были изучены преморбидные характерологические типы личности (табл. 2). 
Т а б л и ц а 2 Распределение больных опийной наркоманией в зависимости от преморбидного типа личности

\begin{tabular}{|l|c|c|c|c|c|c|c|}
\hline \multirow{3}{*}{$\begin{array}{c}\text { Преморбидный тип } \\
\text { личности }\end{array}$} & \multicolumn{2}{|c|}{$\begin{array}{c}\text { Мужчины } \\
(\mathrm{n}=65)\end{array}$} & \multicolumn{2}{|c|}{$\begin{array}{c}\text { Женщины } \\
(\mathrm{n}=66)\end{array}$} & \multirow{2}{*}{$\mathrm{p}$} & \multicolumn{2}{c|}{$\begin{array}{c}\text { Всего } \\
(\mathrm{n}=131)\end{array}$} \\
\cline { 2 - 6 } \cline { 5 - 6 } & абс. & $\%$ & абс. & $\%$ & & абс. & $\%$ \\
\hline Истерический & 6 & 9,2 & 24 & 36,4 & 0,001 & 30 & 22,9 \\
\hline Неустойчивый & 30 & 46,2 & 21 & 31,8 & 0,13 & 51 & 38,9 \\
\hline Психастенический & 3 & 4,6 & 5 & 7,6 & 0,73 & 8 & 6,1 \\
\hline Гипертимный & 11 & 16,9 & 10 & 15,2 & 0,97 & 21 & 16,0 \\
\hline $\begin{array}{l}\text { Импульсивный } \\
\text { (возбудимый) }\end{array}$ & 12 & 18,5 & 3 & 4,5 & 0,03 & 15 & 11,5 \\
\hline $\begin{array}{l}\text { Ригидный } \\
\text { (аффективный) }\end{array}$ & 3 & 4,6 & - & - & & 3 & 2,3 \\
\hline Не определён & - & - & 3 & 4,5 & & 3 & 2,3 \\
\hline
\end{tabular}

Выявлена слабая корреляционная связь между преморбидным типом личности и полом ( $\mathrm{r}=0,27$; $\mathrm{p}=0,002)$.

У многих больных ещё до формирования опийной наркомании имели место признаки девиантного поведения. Отсутствие девиантного поведения достоверно чаще наблюдалось у мужчин $(75,4 \%$ мужчин и 57,6\% женщин; ОШ 2,26; $95 \%$ ДИ 1,07-4,76; $\mathrm{p}=0,05)$ по сравнению с женщинами. Только нарушение школьной дисциплины с более высокой частотой встречалось среди женщин $(18,5 \%$ мужчин и $25,8 \%$ женщин; $\mathrm{p}=0,42)$, чем среди мужчин.

Побеги из дома $(2-3,0 \%)$, уголовно-наказуемые деяния $(1-5 \%)$, проституция $(3-4,5 \%)$ были характерны только для женщин. Случаи приобщения к асоциальной компании с одинаковой частотой отмечались как среди мужчин, так и среди женщин (7,6\% мужчин и 6,2\% женщин; $\mathrm{p}=0,98)$. Выявлено, что асоциальные тенденции, имевшие место ещё до формирования опийной наркомании, достоверно чаще встречались в группе женщин $(24,7 \%$ мужчин и 42,4\% женщин; ОШ 2,26; 95\% ДИ 1,07-4,76; $\mathrm{p}=0,05)$, чем в группе мужчин.

При исследовании преморбидной психологической характеристики немаловажное значение имеет и сфера увлечений. Для группы исследуемых мужчин в детском и в подростковом возрастах было характерно наличие различных увлечений. Так, 18 $(27,7 \%)$ больных мужчин увлекались спортом, чаще это были занятиях в секциях бокса, карате, плавания и футбола. В группе женщин лишь 5 (7,6\%) больных посещали кружки танца и музыки.

При формировании структуры личности в ряду социальных факторов большую роль играют и условия воспитания, характер и сфера деятельности, особенности микросоциального окружения до возникновения опийной наркомании.

Анализ проведенного исследования показал, что подавляющее большинство больных мужчин и женщин воспитывались в полных семьях (90,8\% мужчин и 72,7\% женщин; ОШ 3,69; 95\% ДИ 1,36$10,0 ; \mathrm{p}=0,01)$. Удельный вес больных, воспитывающихся в неполных семьях, достоверно повышался в группе женщин (7,7\% мужчин и 27,3\% женщин; ОШ 4,$50 ; 95 \%$ ДИ 1,56-13,0; p=0,007). Причинами неполной семьи, где воспитанием занималась мать, в основном были разводы родителей. Изучение семейных отношений показало, что семьи, в которых часто возникали конфликты, чаще связанные с характерологическими особенностями родителей, достоверно чаще регистрировались в группе женщин (4,6\% мужчин и 21,2\% женщин; ОШ 5,56; $95 \%$ ДИ 1,52-20,4; p=0,01). Случаи жестокого обращения родителей регистрировались в обеих группах $(1,5 \%$ мужчин и 7,6\% женщин; $p=0,22)$, причем в основном они были связаны с алкоголизацией отца. Безнадзорность $(3,1 \%$ мужчин и $3,0 \%$ женщин; $\mathrm{p}=0,62)$ и воспитание по типу «кумир семьи» наблюдались с одинаковой частотой среди больных обеих групп $(12,3 \%$ мужчин и $12,1 \%$ женщин; $\mathrm{p}=0,81)$. Воспитание по типу «кумир семьи» наблюдалось в тех семьях, где исследуемые были единственными детьми либо единственными мальчиками - как, например, в группе мужчин. Родители окружали таких детей чрезмерным вниманием, потворствовали любым прихотям, потакали всем капризам и желаниям. Эмоциональное отвержение детей встречалось также в обеих группах больных $(3,1 \%$ мужчин и $4,5 \%$ женщин; $\mathrm{p}=0,99)$.

Выявлялись существенные межгрупповые различия по количеству больных, которые до формирования опийной наркомании были заняты в различных сферах деятельности. Обращает на себя внимание тот факт, что достоверно большее количество женщин до формирования опийной наркомании нигде не работали $(10,8 \%$ мужчин и $54,5 \%$ женщин; ОШ 9,94; 95\% ДИ 3,96-25,0; p=0,0001). Профессионально-трудовой занятости в таких сферах деятельности, как транспорт, силовые структуры, спорт, строительство, в группе женщин не наблюдалось. В сфере обслуживания были задействованы как мужчины, так и женщины $(13,8 \%$ мужчин и $25,8 \%$ женщин; $\mathrm{p}=0,14)$.

\section{ВЫВОДЫ}

Таким образом, сравнительное изучение совокупности предшествующих биологических и социально-психологических факторов, способных повлиять на последующее формирование опийной наркомании, выявило ряд гендерных различий. Следует отметить важную роль наследственной отягощенности наркологической патологией, которая достоверно чаще встречалась в группе больных женщин, среди которых выявлена достоверная корреляционная связь между полом и наследственной отягощенностью. Основная часть больных ещё до формирования опийной наркомании в качестве первых эйфоризирующих средств употребляла алкоголь, почти половина исследуемых мужчин - гашиш. Нами была выявлена корреляция между возрастом употребления алкоголя и полом. Эпизодически употребляли гашиш достоверно большее количество мужчин, чем женщин. Между характером приёма гашиша до приобщения к опиатам и полом также обнаружена достоверная корреляционная связь. Первые пробы наркотических веществ происходили в различных ситуациях. 
Так, достоверно большее количество женщин впервые приняли наркотик в компании наркозависимых друзей своего наркозависимого мужа или сожителя. Значимым фактором явилось то, что достоверно большая доля женщин начали первый приём опиатов с героина, который отличается самой высокой наркогенностью среди опиатов. Принимать героин сразу с внутривенного приёма также начали достоверно большее число женщин, тогда как мужчины достоверно чаще начали прием опиатов перорально.

Вероятность быстрого вовлечения личности в процесс наркотизации увеличивалась при наличии истерических черт характера, истерические проявления достоверно чаще регистрировались у женщин, импульсивные (возбудимые) черты характера достоверно чаще отмечались у мужчин. Асоциальные тенденции, отмечавшиеся ещё до формирования опийной наркомании, достоверно чаще регистрировались у женщин. Условия семейного воспитания, характер и сфера трудовой деятельности исследуемых также имели гендерные различия. Достоверно большее количество женщин воспитывались в неполных семьях. Частые конфликты в семье, в основном связанные с характерологическими особенностями родителей, также достоверно чаще регистрировались у женщин. Ещё до формирования наркоманической зависимости более половины исследуемых женщин не занимались трудовой деятельностью, тогда как почти все мужчины были заняты в различных сферах деятельности.

\section{КОНФЛИКТ ИНТЕРЕСОВ}

Автор декларирует отсутствие явных и потенциальных конфликтов интересов в связи с публикацией данной статьи.

\section{ИСТОЧНИК ФИНАНСИРОВАНИЯ}

Автор заявляет об отсутствии финансирования при проведении исследования.

\section{СООТВЕТСТВИЕ ПРИНЦИПАМ ЭТИКИ}

Работа соответствует этическим стандартам Хельсинской декларации ВМА (протокол заседания локального этического комитета при ТашИУВ № 7/11 от 29.03.2017).

\section{ЛИТЕРАТУРА}

1. Альтшулер В.Б., Мохначев С.О. Гендерные аспекты наркологических заболеваний / под ред. Н.Н. Иванца, И.П. Анохиной, М.А. Винниковой. М.: ГЭОТАР-Медиа, 2008: 396-397.
2. Бартош Т.П., Бартош О.П., Мычко М.В. Акцентуации характера девочек-подростков разных этнических групп Магаданской области, склонных к употреблению алкоголя. Наркология. 2015; 2: 24-28.

3. Бохан Н. А., Семке В. Я. Коморбидность в наркологии. Томск : Изд-во Том. ун-та, 2009: 510.

4. Кирина Ю.Ю., Лопатин А.А., Селедцов А.М. Факторы, способствующие формированию девиантного поведения у несовершеннолетних с наркотическими расстройствами. Сибирский вестник психиатрии и наркологии. 2015; 2 (87): 43-47.

5. Кочаргина Г.А., Кошкина У.Ф. Особенности наркотизма у женщин. Медико-биологические и социальные аспекты наркологии. М., 1997: 43-46.

6. Мингазов А.Х., Васильев В.Н. Резистентное течение опийной наркомании. Сибирский вестник психиатрии и наркологии. 2016; 3 (92): 29-32.

7. Рохлина М.Л., Мохначев С.О. Особенности формирования и клиники героиновой наркомании с учетом половых различий. М., 2003: 29.

8. Рохлина М.Л. Аффективные расстройства при героиновой наркомании на разных этапах заболевания. Наркология. 2005; $2: 36-39$.

9. Садвакасова Г.А. Особенности формирования зависимости от опиоидов у женщин, проживающих в Республике Казахстан. Вопросы наркологии Казахстана. Павлодар, 2008; 8 (3): 70-77.

10. Сахаров А.В., Говорин Н.В. Гендерные различия лиц с алкогольной зависимостью, госпитализированных в наркологический стационар по поводу синдрома отмены. Сибирский вестник психиатрии и наркологии. 2014; 1 (82): 28-32.

11. Ядрова Т.В. Психические расстройства у женщин, злоупотребляющих психоактивными веществами и совершивших правонарушения: автореф. дис. ... к.м.н. М., 2005: 25.

12. Bokhan N. A., Ovchinnikov A. A. Dissociative model of addictions formation. Saint-Louis, MO, USA: Publishing House Science and Innovation Center, 2014: 32.

13. Dech H., Ndetei D., Machleidt W. Social change, globalization and transcultural psychiatry-some considerations from a study on women and depression. Seishin Shinkeigaku Zasshi. 2003; 105 (1): 17-27.

14. Gerevich J., Bacskai E., Farkas L. et al. A case report: pavlovian conditioning as a risk factor in heroin «overdose» death. Harm. Reduction J. 2005; 2: 11-14.

15. Greenfield S., Sugarman D., Fried C. et al. Group therapy for women with substance use disorders: results from the Women's Recovery Group Study). Drug Alcohol Dependence. 2014; 142: 245-253.

16. Lynch W., Roth M., Carroll M. Biological basis of sex differences in drug abuse: preclinical and clinical studies. Psychopharmacology. 2002; 164 (2): 121-137.

Шигакова Фания Анваровна, д.м.н., ассистент кафедры психиатрии и психотерапии.

Шигакова Фания Анваровна, Dr.FShigakova@gmail.com 
УДК 616.89-008.441.33-055.1/2

For citation: Shigakova F.A. Role of gender differences in mechanisms of opium addiction formation. Siberian Herald of Psychiatry and Addiction Psychiatry. 2017; 3 (96): 21-26. https://doi.org/10.26617/1810-3111-2017-3(96)-21-26

\title{
Role of gender differences in mechanisms of opium addiction formation Shigakova F.A.
}

\author{
Tashkent Institute of Postgraduate Medical Education \\ Parkent Street 51, 100007, Tashkent, Uzbekistan
}

\section{ABSTRACT}

Objective: to analyze causes and mechanisms of development of opium addiction with account for gender differences. Material: In the Republican Narcological Center between 2010 and 2015131 patients with opium addiction were treated. The main group included 66 female patients aged 18-56 years. Group of comparison included 65 males aged 23-50 years. Results: The correlation analysis of causes and mechanisms of opium addiction formation with account for gender differences revealed reliable correlation $(\mathrm{r}=0.31 ; \mathrm{p}=0.003)$ between gender and family history, age of alcohol consumption and gender $(\mathrm{r}=0.23 ; \mathrm{p}=0.02)$. The reliably larger number of women used drug for the first time in the company of drug addicted friends, drug addicted husband or cohabitant. Significant factors were that reliably larger number of women began the first use of opiates with heroin which is characterized by the highest narcogenicity among opiates. Many patients before opium addiction formation had signs of deviant behavior. Absence of deviant behavior was reliably more often observed in men (75.4\% of males and 57.6\% of females; OR 2.26; $95 \%$ CI 1.07-4.76; $\mathrm{p}=0.05$ ) in comparison with women. Before drug addiction formation more than a half of female probands did not work whereas almost all men were engaged in various areas of activities.

Keywords: sex, correlation, gender differences, opium addiction.

\section{REFERENCES}

1. Altshuler V.B., Mokhnachev S.O. Gendernye aspekty narkologicheskih zabolevaniy [Gender aspects of narcological diseases]. N.N. Ivanets, I.P. Anokhina, M.A. Vinnikova, eds. M.: GEOTAR-Media, 2008: 396-397 (in Russian).

2. Bartosh T.P., Bartosh O.P., Mychko M.V. Aktsentuatsii haraktera devochek-podrostkov raznykh etnicheskikh grupp Magadanskoy oblasti, sklonnykh $\mathrm{k}$ upotrebleniyu alkogolya [Character accentuations observed in alcohol susceptible adolescent girls of different ethnic origin residing in Magadan region]. Narkologiya - Narcology. 2015; 2: 24-28 (in Russian).

3. Bokhan N.A., Semke V.Ya. [Co-morbidity in Addiction Psychiatry]. Tomsk: Publishing House of Tomsk University, 2009. 510 p. (in Russian).

4. Kirina Yu.Yu., Lopatin A.A., Seledtsov A.M. Faktory, sposobstvuyuie formirovaniyu deviantnogo povedeniya u nesovershenoletnikh s narkoticheskimi rasstroystvami [Factors contributing to formation of deviant behavior in minors with substance-related disorders]. Sibirskiy vestnik psychiatry i narkologii - Siberian Herald of Psychiatry and Addiction Psychiatry. 2015; 2 (87): 43-47 (in Russian).

5. Kochergina G.A., Koshkina L.F. Osobennosti narkotizma u zhenschin. Mediko-biologicheskie i sotsialyie aspektyi narkologii [Characteristics of narcotizm in women. Medicobiological and social aspects of narcology]. M., 1997: 43-46 (in Russian).

6. Mingazov A.Kh., Vasiliev V.N. Rezistentnoe techenie opiynoy narkomanii [Resistant course of opium addiction]. Sibirskiy vestnik psychiatry i narkologii - Siberian Herald of Psychiatry and Addiction Psychiatry. 2016; 3 (92): 29-32 (in Russian).

7. Rokhlina M.L., Mokhnachev S.O. Osobennosti formirovaniya i kliniki geroinovoy narkomanii s uchetom polovyih razlichiy [Characteristics of formation and clinical picture of heroin addiction with account for gender differences]. M., 2003: 29 (in Russian).

8. Rokhlina M.L. Affektivnye rasstroystva pri geroinovoy narkomanii na raznykh etapakh zabolevaniya [Affective disorders in heroin addiction at different stages of the disease]. Narkologiya Narcology. 2005: 12: 36-39 (in Russian).
9. Sadvakasova G.A. Osobennosti formorovaniya zavisimosti ot opioidov u zhenschin, prozhivayauschih v Respublike Kazakhstan [Characteristics of opioid addiction formation in women residing in the Republic of Kazakhstan]. Voprosyi narkologii Kazakhstani - Issues of Narcology of Kazakhstan. 2008; 8 (3): 7077 (in Russian).

10. Sakharov A.V., Govorin N.V. Gendernye razlichiya lits s alkogolnoy zavisimostyu, gospitalizirovannykh $\mathrm{v}$ narkologicheskiy statsionar po povodu sindroma otmeny [Gender differences of persons with alcohol dependence, hospitalized to narcological hospital for alcohol withdrawal syndrome]. Sibirskiy vestnik psychiatry i narkologii - Siberian Herald of Psychiatry and Addiction Psychiatry. 2014; 1 (82): 28-32 (in Rusian).

11. Yadrova T.V. Psihicheskie rasstroystva u zhenschin, zloupotreblyayuschih psihoaktivnymi vaschestvsmi i sovershivshimi pravonarusheniy [Mental disorders in women abusing psychoactive substances and having committed offences]. Avtoref. dis. .. k.m.n. [Abstract of PhD thesis]. M., 2005: 25 (in Russian).

12. Bokhan N. A., Ovchinnikov A. A. Dissociative model of addictions formation. Saint-Louis, MO, USA: Publishing House Science and Innovation Center, 2014: 32.

13. Dech H., Ndetei D., Machleidt W. Social change, globalization and transcultural psychiatry-some considerations from a study on women and depression. Seishin Shinkeigaku Zasshi. 2003; 105 (1): 17-27.

14. Gerevich J., Bacskai E., Farkas L. et al. A case report: pavlovian conditioning as a risk factor in heroin «overdose» death. Harm. Reduction J. 2005; 2: 11-14.

15. Greenfield S., Sugarman D., Fried C. et al. Group therapy for women with substance use disorders: results from the Women's Recovery Group Study). Drug Alcohol Dependence. 2014; 142: 245-253.

16. Lynch W., Roth M., Carroll M. Biological basis of sex differences in drug abuse: preclinical and clinical studies. Psychopharmacology. 2002; 164 (2): 121-137.

Received April 21.2017

Accepted June 26.2017

Shigakova Faniya A., MD, assistant of Psychiatry and Psychotherapy Department, Tashkent Institute of Postgraduate Medical Education, Tashkent, Uzbekistan. 